\title{
PERFIL SOCIODEMOGRÁFICO, CONDIÇÕES E CARGAS DE TRABALHO DE PROFESSORES DA REDE ESTADUAL DE ENSINO DE UM MUNICÍPIO DA REGIÃO SUL DO BRASIL
}

\author{
SOCIODEMOGRAPHIC PROFILE, CONDITIONS AND WORKLOADS OF STATE TEACHERS IN A \\ MUNICIPALITY IN SOUTHERN BRAZIL
}

PERFIL SOCIODEMOGRÁFICO, CONDICIONES Y CARGAS DE TRABAJO DE MAESTROS DE LA

RED ESTADUAL DE ENSEÑO DE UN MUNICIPIO DE LA REGIÓN SUR DE BRASIL

Natalia Paludeto Guerreiro ${ }^{1}$

Elisabete de Fátima Polo de Almeida Nunes ${ }^{2}$

Alberto Durán González ${ }^{3}$

Arthur Eumann Mesas ${ }^{4}$

Resumo Objetivou-se descrever o perfil sociodemográfico e econômico e analisar as características profissionais, condições de trabalho e cargas de trabalho em professores. Trata-se de um estudo transversal sobre o projeto Pró-Mestre. Foram entrevistados 978 professores do ensino fundamental e do ensino médio das vinte escolas com maior número de professores da rede estadual de ensino da cidade de Londrina/PR, entre agosto de 2012 e julho de 2013. A maioria dos professores entrevistados era do sexo feminino $(68,5 \%)$ e com média de idade de 41,5 anos (DP 10). Quanto às características profissionais, $42,9 \%$ trabalhavam em até dois locais e $64,2 \%$ lecionavam em pelo menos dois turnos. Aspectos como remuneração, quantidade de alunos por sala e infraestrutura foram relatados como negativos (ruim/regular). Em relação às cargas de trabalho, as cargas físicas, fisiológicas e psíquicas, para mais da metade deles, afetam muito sua saúde e condições de trabalho. Esses fatores sinalizaram as condições de trabalho e saúde de professores da rede estadual do Paraná, podendo servir como subsídio para o desenvolvimento de políticas públicas que visem melhorias nesses aspectos.

Palavras-chave trabalho docente; professor; condições de trabalho; cargas de trabalho.
Abstract This study aimed to describe the sociodemographic and economic profile of teachers and analyze their professional characteristics, working conditions and workloads. This is a cross-sectional study of the Pro-Master project. We interviewed 978 primary school and high school teachers of the twenty state schools with more teachers of the city of Londrina/PR, between August 2012 and July 2013. Most of the teachers surveyed were female $(68.5 \%)$ with mean age of 41.5 years (SD 10). As for professional features, $42.9 \%$ worked in up to two places and $64.2 \%$ teach at least two shifts. Issues such as remuneration, amount of students per class and infrastructure were reported as negative (bad/regular). In relation to workloads, physical, physiological and mental burdens, for more than half of them, greatly affect their health and working conditions. These factors signaled the working conditions and health of state teachers of Paraná, and can be useful to support the development of public policies to improve these aspects.

Keywords teaching work; teacher; work conditions; workloads. 


\section{Introdução}

Os professores realizam tarefas que extrapolam as salas de aula, tais como correção de provas, preparo de aulas e atividades que demandam tempo e, na maioria das vezes, precisam ser terminadas em seus domicílios, além de necessitarem estudo contínuo. Todo esse esforço extramuros da escola não é recompensado financeiramente e nem mesmo reconhecido (Codo, 1999). Também não se reflete em valorização por parte da sociedade ou em condições adequadas para o exercício da docência.

Condições de trabalho são as circunstâncias em que o trabalho é realizado e compreendem tanto aspectos do ambiente quanto da sua organização. Quando as condições são precárias e o volume de atividades se torna excessivo, exigindo altas demandas físicas e emocionais, acabam comprometendo a eficiência do professor (Assunção, 2008). Além disso, podem causar efeitos perversos relacionados à saúde, como desgastes físico e psicológico, absenteísmo e até mesmo o abandono da profissão (Cruz et al., 2010).

O cenário de condições precárias para o trabalho acaba por exigir dos professores um sobre-esforço ou uma hipersolicitação de suas funções psicofisiológicas (Gasparini, Barreto e Assunção, 2005). A quantidade de tarefas executadas, denominada carga de trabalho, representa demandas ou exigências psicobiológicas do processo de trabalho que levam ao desgaste do trabalhador (Facchini, 1993). Acrescente-se que as novas exigências e competências requeridas dos professores, juntamente com as mudanças na organização do trabalho, têm causado o aumento dessas cargas de trabalho (Gasparini, Barreto e Assunção, 2006).

Diante dessa conjuntura, torna-se relevante conhecer as características de trabalho e cargas de trabalho de professores para a elaboração de políticas públicas com foco na melhoria das condições de trabalho que terão reflexo na qualidade de vida dos professores e na qualidade do ensino dos estudantes.

O objetivo desta pesquisa foi descrever o perfil sociodemográfico, o econômico, as condições de trabalho e as cargas de trabalho de professores da rede estadual de ensino de Londrina/PR.

\section{Metodologia}

Trata-se de um estudo epidemiológico observacional do tipo transversal, quantitativo, que integra o projeto "Saúde, estilo de vida e trabalho de professores da rede pública do Paraná", o Pró-Mestre.

A população de estudo foi constituída por professores do ensino fundamental e ensino médio de vinte das 72 escolas da rede estadual de ensino da cidade de Londrina, no norte do estado do Paraná. O critério utilizado para 
selecionar as escolas participantes da pesquisa foi por conveniência, por apresentarem maior número de professores atuantes.

A pesquisa 5 contou com o apoio da Prefeitura Municipal de Londrina e do Núcleo Regional de Educação de Londrina (NREL), que enviou ofício para cada uma das escolas comunicando sobre o projeto Pró-Mestre. Após reunião com cada diretor, foi agendada palestra de apresentação dos objetivos e da finalidade do projeto para os professores. Todas as escolas selecionadas aceitaram participar do estudo, e todos os professores que preenchiam os critérios de inclusão foram convidados a participar da pesquisa.

Os critérios de inclusão foram: atuar no ensino fundamental ou médio (regular ou integrado) da rede estadual de ensino, em sala de aula (ativos) e ser responsável pela disciplina; no caso de professores em licença médica (ou de outro tipo), o critério era atuar em sala de aula e retornar às suas atividades no máximo trinta dias após a equipe de coleta finalizar as atividades no colégio.

Foi realizado treinamento com todos os pesquisadores para apresentação da logística da coleta e do instrumento (formulário e questionário), sendo realizado pré-teste para aprimoramento e esclarecimento de dúvidas em dois momentos: antes do estudo piloto, realizado em três colégios estaduais de uma cidade próxima, e, posteriormente, mas antes da coleta de dados, nas escolas estaduais do município de Londrina, que ocorreu entre os meses de agosto de 2012 e julho de 2013.

As entrevistas tiveram a duração média de cinquenta minutos, ou seja, uma hora-atividade do professor, e, nesse tempo, tanto o formulário (entrevista) quanto o questionário foram aplicados. Porém, os professores que não conseguiram terminar o questionário no momento da entrevista puderam devolvê-lo posteriormente. Foi considerada perda após cinco tentativas de agendamento em momentos diferentes.

Para este estudo, foram utilizadas as seguintes variáveis: a) caracterização sociodemográfica e econômica - sexo, idade, situação conjugal, raça/cor autorreferida, grau de instrução e renda familiar aproximada -, obtida por meio do questionário; b) características profissionais - número de locais de trabalho, períodos que leciona, níveis de ensino que leciona, disciplinas ministradas, atuação, tipo de contrato, carga horária semanal total como professor e carga horária semanal com alunos; c) condições de trabalho utilizou-se escala com perguntas relacionadas às condições do ambiente e da organização do trabalho, sendo respondidas de acordo com a legenda: ruim, regular, bom/boa e excelente; d) cargas de trabalho - foi confeccionada uma escala de acordo com as definições de cargas de trabalho e suas divisões (cargas físicas, químicas, mecânicas, biológicas, fisiológicas e psíquicas), propostas por Facchini (1993) e adaptadas para a atividade docente, utilizando-se a legenda: não afeta, afeta pouco e afeta muito, para cada pergunta. Essas variáveis foram obtidas por meio do formulário (entrevista). 
Os dados foram duplamente digitados em um banco criado no programa Epi Info, versão 3.5.4, e analisados utilizando-se o programa SPSS, versão 15.0. Foi realizada análise descritiva, por meio de distribuição das frequências de variáveis categóricas e média (desvio padrão - DP) de variáveis contínuas para descrição da população.

O projeto foi aprovado pelo Comitê de Ética em Pesquisa da Universidade Estadual de Londrina (UEL), com parecer registrado na Plataforma Brasil de Projetos de Pesquisa envolvendo Seres Humanos (CAAE nº 01817412.9.0000.5231). Os entrevistados foram devidamente orientados quanto aos objetivos da pesquisa e, em seguida, o Termo de Consentimento Livre e Esclarecido (TCLE) foi apresentado e explicado a todos os professores.

\section{Resultados}

Nas escolas estaduais pesquisadas atuavam 1.505 professores. Desses, 379 foram excluídos por não preencherem os critérios de inclusão. Entre os 1.126 professores incluídos, 65 foram excluídos por estarem de licença e não retornarem em até trinta dias após a saída da equipe de coleta do colégio. A população de estudo foi de 1.061 professores, dos quais 83 foram considerados perdas, tanto pelo insucesso no contato para agendamento da entrevista após cinco tentativas $(1,9 \%)$ quanto por recusas $(5,9 \%)$. Ao final, $978(92,2 \%)$ professores foram entrevistados (Figura 1).

Fluxograma de seleção dos professores das escolas estaduais entrevistados na pesquisa. Londrina, PR, 2012-2013

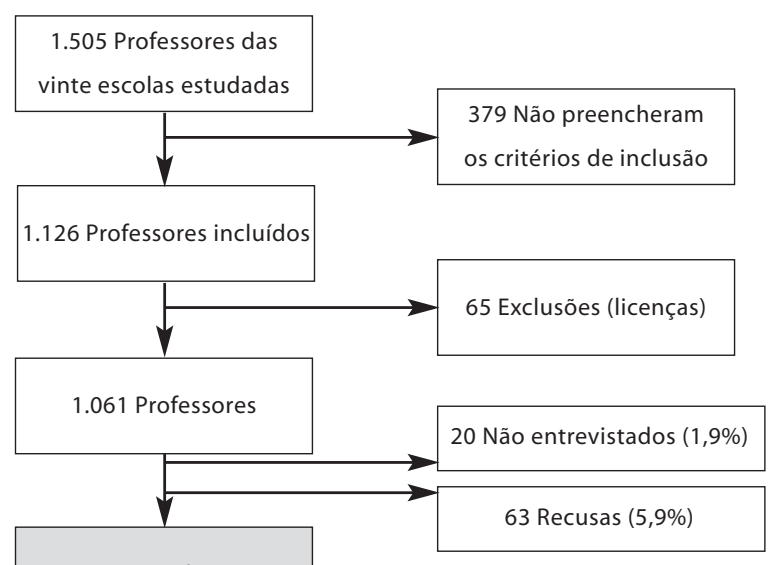

978 Entrevistados (92,2\%)

Fonte: Os autores 
Dos professores entrevistados, a maioria era do sexo feminino $(68,5 \%)$, de cor branca (74,5\%) e com média de idade de 41,5 anos (DP 10). Quanto à situação conjugal, $60 \%$ viviam com companheiro. Já a renda familiar aproximada ficou na faixa de $\mathrm{R} \$ 5.001,00$ ou mais $(40,5 \%)$. Dos entrevistados, 73,1 \% possuíam pós-graduação lato sensu (especialização) (Tabela 1).

Tabela 1

\begin{tabular}{|c|c|c|}
\hline Variáveis & $\mathbf{N}$ & $\%$ \\
\hline \multicolumn{3}{|l|}{ Sexo } \\
\hline Masculino & 308 & 31,5 \\
\hline Feminino & 670 & 68,5 \\
\hline \multicolumn{3}{|l|}{ Idade } \\
\hline Até 29 anos & 130 & 13,3 \\
\hline $30+40$ anos & 295 & 30,2 \\
\hline $40+49$ anos & 330 & 33,7 \\
\hline $49+59$ anos & 183 & 18,7 \\
\hline $59+68$ anos & 40 & 4,1 \\
\hline \multicolumn{3}{|l|}{ Situação conjugal* } \\
\hline Com companheiro & 571 & 60,0 \\
\hline Sem companheiro & 381 & 40,0 \\
\hline \multicolumn{3}{|l|}{ Raça/cor autorreferida* } \\
\hline Branco & 720 & 74,5 \\
\hline Não branco & 247 & 25,5 \\
\hline \multicolumn{3}{|l|}{ Grau de instrução* } \\
\hline Bacharel/licenciatura & 124 & 12,8 \\
\hline Pós-graduação (Especialização) & 708 & 73,1 \\
\hline Pós-graduação (Mestrado/Doutorado) & 135 & 13,9 \\
\hline Pós-graduação em andamento & 2 & 0,2 \\
\hline \multicolumn{3}{|l|}{ Renda mensal familiar aproximada* $\dagger$} \\
\hline $\mathrm{R} \$ 2.000,00$ ou menos & 76 & 7,9 \\
\hline Entre $R \$ 2.001,00$ e $R \$ 3.000,00$ & 165 & 17,0 \\
\hline Entre $R \$ 3.001,00$ e $R \$ 5.000,00$ & 335 & 34,6 \\
\hline$R \$ 5.001,00$ ou mais & 392 & 40,5 \\
\hline
\end{tabular}

* Os valores diferem do no total (978) pela ausência de informação para as variáveis indicadas; $†$ Valor do salário mínimo em 2013: R\$ 678,00 - Fonte: http://portal.mte.gov.br/sal_min/. Cotação do dólar em 2013: média de $\mathrm{R} \$ 2,16$ - Fonte: www.acinh.com.br/cotacao.html/. 
No tocante às características profissionais (Tabela 2), destaca-se que $30 \%$ dos docentes trabalhavam em três ou mais locais, e 16,6\% em três turnos. Quando questionados sobre as disciplinas ministradas, $87,4 \%$ atuavam em apenas uma área de conhecimento, e 12,6\% em mais de uma área de conhecimento - área de exatas e humanas, por exemplo.

Ao analisar a atuação profissional dos entrevistados, 9,5\% eram professores e possuíam outra ocupação paralela, e 4,9\% eram professores e possuíam outra ocupação na área da educação. Com relação ao tipo de vínculo, $31,3 \%$ relataram não ser concursados (não estatutários). Quanto à carga horária como professor, observou-se que 62,5\% trabalhavam de 21 a 40 horas semanais, e $71,1 \%$ permaneciam de 17 a 36 horas semanais em contato com alunos.

Tabela 2

\begin{tabular}{lll}
\hline $\begin{array}{l}\text { Distribuição das características profissionais dos professores da rede estadual de } \\
\text { ensino. Londrina, PR, 2012-2013 }\end{array}$ & N \\
\hline Variáveis & 265 & \\
\hline Número de locais de trabalho & 420 & 27,1 \\
Um & 177 & 42,9 \\
Dois & 116 & 18,1 \\
Três & 188 & 11,9 \\
Acima de três & 628 & 19,2 \\
Períodos que leciona & 162 & 64,2 \\
Um turno & & 16,6 \\
Dois turnos & 212 & \\
Três turnos & 169 & 21,7 \\
Níveis de ensino em que leciona & 408 & 17,3 \\
Ensino fundamental & 41 & 41,7 \\
Ensino médio & 80 & 4,2 \\
Ensino fundamental e médio & & 9,0 \\
Ensino fundamental e outros & & \\
Ensino médio e outros & & \\
Ensino fundamental, médio e outros & & \\
\hline
\end{tabular}


Continuação - Tabela 2

Distribuiçăo das características profissionais dos professores da rede estadual de ensino. Londrina, PR, 2012-2013

\begin{tabular}{|c|c|c|}
\hline Variáveis & $\mathbf{N}$ & $\%$ \\
\hline \multicolumn{3}{|l|}{ Disciplinas } \\
\hline Uma área de conhecimento & 855 & 87,4 \\
\hline Mais de uma área de conhecimento & 123 & 12,6 \\
\hline \multicolumn{3}{|l|}{ Atuação } \\
\hline Exclusivamente professor & 837 & 85,6 \\
\hline Professor e outra ocupação & 93 & 9,5 \\
\hline Professor e outra ocupação na área da educação & 48 & 4,9 \\
\hline \multicolumn{3}{|l|}{ Tipo de contrato } \\
\hline Estatutário & 672 & 68,7 \\
\hline Não estatutário & 306 & 31,3 \\
\hline \multicolumn{3}{|l|}{ Carga horária semanal total como professor } \\
\hline Até 20 horas & 163 & 16,7 \\
\hline $20 \nmid 40$ horas & 611 & 62,5 \\
\hline $40 \nmid 70$ horas & 204 & 20,8 \\
\hline \multicolumn{3}{|l|}{ Carga horária semanal com alunos* } \\
\hline Até 16 horas & 163 & 16,7 \\
\hline $16 \nmid 30$ horas & 396 & 40,7 \\
\hline $30 \uparrow 36$ horas & 296 & 30,4 \\
\hline
\end{tabular}

* Total $=974$

Fonte: Os autores.

Em relação às condições de trabalho (Tabela 3), 92,3\% dos professores relataram ter bom/excelente relacionamento com os superiores, 96,3\% afirmaram que o relacionamento com os colegas também era bom/excelente, assim como o relacionamento com os alunos $(89,4 \%)$ foi considerado positivo. Quanto ao relacionamento com os pais de alunos, entre os que relataram possuir tal relacionamento, 78,8\% disseram ser bom/excelente. Porém, 33,2\% dos professores referiram que o contato com os pais dos alunos inexistia. 
Tabela 3

\begin{tabular}{|c|c|c|c|c|}
\hline \multirow[t]{2}{*}{ Categorias } & Ruim & Regular & Bom & Excelente \\
\hline & $\mathrm{n}(\%)$ & $\mathrm{n}(\%)$ & $\mathrm{n}(\%)$ & $\mathrm{n}(\%)$ \\
\hline Relacionamento com superiores (diretores/supervisores) & $6(0,6)$ & $69(7,1)$ & $503(51,4)$ & $400(40,9)$ \\
\hline Relacionamento com colegas & $2(0,2)$ & $35(3,6)$ & $557(57,0)$ & $384(39,3)$ \\
\hline Relacionamento com alunos & $6(0,6)$ & $98(10,0)$ & $663(67,8)$ & $211(21,6)$ \\
\hline Relacionamento com pais de alunos* & $14(2,1)$ & $125(19,1)$ & $432(66,2)$ & $82(12,6)$ \\
\hline Oportunidade para expressar suas opiniões no trabalho† & $30(3,1)$ & $151(15,5)$ & $507(52,2)$ & $284(29,2)$ \\
\hline Motivação para chegar ao trabalho & $28(2,9)$ & $157(16,1)$ & $562(57,5)$ & $231(23,6)$ \\
\hline Remuneração com relação ao trabalho realizado† & $168(17,2)$ & $446(45,6)$ & $340(34,8)$ & $23(2,4)$ \\
\hline Equilíbrio entre sua vida profissional e pessoal & $51(5,2)$ & $223(22,8)$ & $565(57,8)$ & $139(14,2)$ \\
\hline Quantidade de alunos por sala de aula & $288(29,4)$ & $381(39,0)$ & $273(27,9)$ & $36(3,7)$ \\
\hline Manutenção e conservação dos materiais, equipamentos & $115(11,8)$ & $381(39,0)$ & $424(43,4)$ & $58(5,9)$ \\
\hline \multicolumn{5}{|l|}{ e mobiliários } \\
\hline Infraestrutura disponível para descanso/estudo e & $119(12,2)$ & $394(40,3)$ & $402(41,1)$ & $62(6,3)$ \\
\hline \multicolumn{5}{|l|}{ preparo de atividades durante a hora-atividade $\dagger$} \\
\hline Infraestrutura predial & $108(11,0)$ & $396(40,5)$ & $412(42,1)$ & $62(6,3)$ \\
\hline
\end{tabular}

* Não se aplica $=325(33,2 \%) ;$ † Os valores diferem do no total (978).

Fonte: Os autores.

Tanto a oportunidade para expressar as opiniões $(81,4 \%)$ quanto a motivação para chegar ao trabalho $(81,1 \%)$ e o equilíbrio entre a vida profissional e pessoal $(72,0 \%)$ foram considerados bons/excelentes (Tabela 3$)$.

Aspectos como remuneração $(62,8 \%)$, quantidade de alunos por sala $(68,4 \%)$, manutenção e conservação de equipamentos $(50,8 \%)$, infraestrutura para o preparo de atividades $(52,5 \%)$ e infraestrutura predial $(51,5 \%)$ foram relatados como negativos (ruim/regular) (Tabela 3).

Já as cargas de trabalho (Tabela 4), as cargas físicas e a exposição ao ruído dentro da sala de aula afetam muito $61,5 \%$ dos professores. Quanto às cargas químicas, $78,2 \%$ disseram que a exposição ao pó de giz afeta de alguma maneira (afeta pouco ou afeta muito), e para $44,4 \%$ afeta muito. 
Tabela 4

Distribuição das cargas de trabalho autorreferidas pelos professores da rede estadual de ensino. Londrina, PR, 2012-2013

\begin{tabular}{|c|c|c|c|}
\hline \multirow[t]{2}{*}{ Categorias } & Não afeta & Afeta pouco & Afeta muito \\
\hline & $n(\%)$ & $\mathrm{n}(\%)$ & $n(\%)$ \\
\hline \multicolumn{4}{|l|}{ Cargas físicas } \\
\hline Exposição a ruídos dentro da sala de aula & $50(5,1)$ & $327(33,4)$ & $601(61,5)$ \\
\hline Exposição a ruídos na escola & $149(15,2)$ & $460(47,0)$ & $369(37,7)$ \\
\hline Exposição a ruídos fora da escola & $422(43,1)$ & $429(43,9)$ & $127(13,0)$ \\
\hline \multicolumn{4}{|l|}{ Cargas químicas } \\
\hline Exposição ao pó de giz* & $213(21,8)$ & $330(33,8)$ & $434(44,4)$ \\
\hline Exposição a poeiras* & $236(24,2)$ & $390(39,9)$ & $351(35,9)$ \\
\hline \multicolumn{4}{|l|}{ Cargas biológicas } \\
\hline Condições de higiene do local de trabalho & $389(39,8)$ & $445(45,5)$ & $144(14,7)$ \\
\hline Exposição a vírus, bactérias, fungos e parasitas & $345(35,3)$ & $372(38,0)$ & $261(26,7)$ \\
\hline \multicolumn{4}{|l|}{ Cargas mecânicas } \\
\hline Condições para carregar o material didático & $262(26,8)$ & $395(40,4)$ & $321(32,8)$ \\
\hline \multicolumn{4}{|l|}{ Cargas fisiológicas } \\
\hline Tempo em que permanece em pé & $148(15,1)$ & $315(32,2)$ & $515(52,7)$ \\
\hline Condições para escrever no quadro de giz & $210(21,5)$ & $351(35,9)$ & $417(42,6)$ \\
\hline Posição do corpo com relação ao mobiliário e aos & $297(30,4)$ & $422(43,1)$ & $259(26,5)$ \\
\hline \multicolumn{4}{|l|}{ equipamentos } \\
\hline \multicolumn{4}{|l|}{ Cargas psíquicas } \\
\hline Ritmo e intensidade do trabalho & $120(12,3)$ & $366(37,4)$ & $429(50,3)$ \\
\hline Número de tarefas realizadas e a atenção e & $151(15,4)$ & $324(33,2)$ & $502(51,4)$ \\
\hline \multicolumn{4}{|l|}{ responsabilidade que exigem* } \\
\hline Tempo disponível para o preparo das atividades & $109(11,1)$ & $273(27,9)$ & $596(60,9)$ \\
\hline
\end{tabular}

* Total $=977$

Fonte: Os autores.

As cargas biológicas - condições de higiene $(45,5 \%)$ e exposição a microrganismos em ambientes fechados, como banheiros e salas de aula $(38,0 \%)$ - e a carga mecânica - condições para carregar o material didático $(40,4 \%)$ foram referidas como "afetam pouco".

As cargas fisiológicas - o tempo que permanecem em pé $(52,7 \%)$ e as condições para escrever no quadro de giz $(42,6 \%)$ - afetam muito os professores. 
Para as cargas psíquicas, a maioria dos entrevistados relatou que o ritmo e a intensidade do trabalho (50,3\%), o número de tarefas realizadas e a atenção e a responsabilidades exigidas $(51,4 \%)$, assim como o tempo disponível para preparar as atividades $(60,9 \%)$ afetam muito sua saúde e suas condições de trabalho.

\section{Discussão}

Os professores da rede estadual de ensino de Londrina representaram uma população relativamente jovem, composta, em sua maioria, por mulheres brancas, com companheiro e com pós-graduação em nível de especialização.

Segundo Codo (1999), a grande presença feminina na profissão docente está relacionada à expansão do sistema educacional no país a partir da segunda metade do século XX, acompanhada da necessidade de recrutamento de trabalhadores para o ensino. Apesar de ser uma atividade desempenhada por ambos os sexos, naquela época, acreditava-se que a mulher poderia desenvolver melhor essa tarefa, devido ao fato de já exercer em seu domicílio o papel de cuidadora e educadora dos filhos, ou seja, aspectos considerados inerentes à atividade docente.

Todos os professores do estudo possuíam grau de instrução de nível superior, e 71,5\% deles eram pós-graduados (nível especialização). Isso pode estar relacionado à aprovação da Lei de Diretrizes e Bases da Educação, em dezembro de 1996, que passou a exigir de todos os professores, em todos os níveis de ensino, formação de curso superior.

Quanto às características profissionais, verificou-se elevada carga horária semanal como professor. A maior parte dos docentes atuava em até dois locais de trabalho, lecionava tanto no ensino fundamental quanto no ensino médio, e a maioria trabalhava em pelo menos dois turnos. Destaca-se que 12,6\% dos professores ministravam disciplinas em mais de uma área de conhecimento, ou seja, enquanto em uma turma ensinava disciplinas da área de humanas, em outra ensinava disciplinas da área de exatas, por exemplo. Além disso, 9,5\% dos professores exerciam outras atividades remuneradas além da docência.

Estudo realizado com professores da rede pública estadual em todas as regiões do Brasil (Codo, 1999) identificou que 18,2\% dos professores apresentavam carga mental elevada e, segundo o autor, várias características do trabalho apareceram associadas a ela, tais como: quantidade de empregos, número de turmas, níveis de ensino diversos e quantidade de disciplinas ministradas, entre outras. A carga mental é resultante de fatores nocivos decorrentes das condições, organização e relação com o trabalho, que podem causar desgaste, cansaço, esgotamento e ausência de prazer na execução de tarefas (Codo, 1999). 
Ainda segundo esse autor, professores que possuem outra atividade remunerada (além do trabalho na escola) ou que trabalham em mais de um colégio sentem mais a carga mental no trabalho do que aqueles que possuem apenas um emprego. Isso está presente tanto nos que lecionam vinte horas semanais quanto naqueles que trabalham quarenta horas semanais, com o impacto um pouco maior nesses últimos. Isso significa que ter carga horária semanal de quarenta horas e trabalhar em apenas um local é um pouco menos impactante do que trabalhar vinte horas em dois locais de trabalho, pois o fato de ter dois empregos ou ter que complementar a carga horária em outra escola implica maior deslocamento e adaptação a ambientes diferentes, ou seja, envolve mais relacionamentos e criação de vínculos, planejamento e preparo de atividades (Codo, 1999).

Com relação ao tipo de contrato, $68,7 \%$ dos professores eram estatutários e 31,3\% não estatutários, ou seja, são contratados de forma precária, sem a garantia de benefícios concedidos aos professores estatutários. Para Matias e Abib (2007), o Estado, sob influência neoliberal, retira e diminui benefícios e direitos dos trabalhadores, precarizando, dessa forma, seus vínculos e aumentando a carga de trabalho.

A flexibilização do trabalho, de acordo com Franco, Druck e Seligmann-Silva (2010), diluiu a nítida separação entre os incluídos e os excluídos, causando uma desestabilização no mundo do trabalho, atingindo, hoje, todos os que necessitam do trabalho para sobreviver.

Desde a década de 1980, essa desestabilização, caracterizada por demissões em massa, teve como consequência a admissão de trabalhadores por meio de formas precarizadas de contratação, por exemplo, os contratos por tempo determinado (Franco, Druck e Seligmann-Silva, 2010). No caso desta pesquisa, como citado anteriormente, essa é a forma de contratação de boa parte dos professores.

Esses autores complementam trazendo as dimensões desse processo: a primeira diz respeito aos vínculos de trabalho e relações contratuais (perda dos direitos trabalhistas); a segunda é referente à organização e às condições de trabalho (ritmo intenso de trabalho, pressão, competitividade); a terceira está relacionada com a precarização da saúde dos trabalhadores; a quarta diz respeito à fragilização do reconhecimento social, da valorização simbólica e do processo de construção das identidades individual e coletiva; e a quinta se refere à representação e à organização coletiva (sindical) (Franco, Druck e Seligmann-Silva, 2010).

Quanto às condições de trabalho, os relacionamentos com os superiores, com os outros professores e com os alunos foram considerados bons ou excelentes para a maioria dos professores. Segundo Dejours, relações de trabalho são "todos os laços humanos criados pela organização do trabalho: relações com as chefias, com a supervisão, com os outros trabalhadores - e que são às vezes desagradáveis, até insuportáveis" (1992, p. 75). Para um ambiente 
empresarial, uma indústria, uma fábrica, essa definição, na maioria das vezes, é muito real, uma vez que são locais em que o trabalho é submetido a um ritmo intenso, visando à produtividade, aos rendimentos, aos prêmios e bonificações, gerando ansiedade no trabalhador devido às pressões das hierarquias e competições entre os colegas de trabalho (Dejours, 1992).

O caso dos professores é um pouco diferente. Embora tenham que mostrar produtividade, cumprir um programa e um cronograma, eles possuem certo controle e autonomia para a realização de suas tarefas (Codo, 1999). O controle e a autonomia na atividade docente merecem destaque por existirem limites relacionados à atuação direta, com referência ao material de apoio disponibilizado em cada escola e no que concerne à autonomia para ajustar o número de alunos em sala de aula. Somam-se, também, as avaliações de desempenho profissional internas e externas, que possibilitam progressões de carreira. Majoritariamente, as políticas de avaliação docente têm a perspectiva da responsabilização docente e utilizam apenas indicadores de desempenhos estudantis (Santos et al., 2012).

O trabalho docente, de certa forma, não é fragmentado e, portanto, não exige dependência nem contato frequente com os demais professores, podendo ser reduzidos, dessa forma, os problemas de relacionamento no trabalho, sobressaindo a cooperação entre eles (Codo, 1999). Isso pode explicar o fato de que, para mais de $80 \%$ dos professores, as relações com os superiores e outros professores foram consideradas positivas.

Por outra parte, o relacionamento com os alunos ocorre de forma mais intensa. Essa é outra característica que diferencia o processo de trabalho de uma indústria do processo de trabalho no ambiente escolar, pois na relação professor-aluno existe uma forte participação desses últimos no processo de aprendizado (Pena, 2011; Pena e Minayo-Gomez, 2010). Na atividade docente há uma relação direta do aluno com o professor, uma simultaneidade, ou seja, ao mesmo tempo em que se produz ou se executa a atividade, deve haver uma coprodução, e para se obter o resultado final (processo de aprendizagem) a atitude/participação do aluno é fundamental.

Quanto ao relacionamento com pais de alunos, para os professores que afirmaram possuir tal contato, mais de 70\% disseram que ele é bom ou excelente, porém para 33,2\% dos docentes esse contato não existe.

De acordo com Assunção e Oliveira (2009), segundo os professores, os pais, hoje, são mais exigentes e valorizam mais a educação, no entanto, valorizam menos os professores e têm menos tempo para a educação e acompanhamento dos filhos. O fato é que os pais transferiram para a escola e os professores a responsabilidade de ensinar aos seus filhos não só o conteúdo curricular, como também a disciplina, outros valores essenciais à formação humana. Se tudo vai bem, os filhos são considerados bons alunos, porém, se vai mal, o professor é julgado como mau educador (Esteve, 1999). 
Por sua vez, na visão dos pais, conforme avaliado em pesquisa qualitativa realizada com pais de alunos com dificuldade de aprendizado e profissionais da educação de uma escola pública da cidade de São Paulo (Giorgion, 2011), existem vários motivos que podem levá-los a se distanciar da escola. No estudo, a escola menciona os pais como responsáveis por essa dificuldade de relacionamento. Já os pais, entre outros motivos, culpabilizam a escola por essa ausência. Os pais mencionam diversos problemas, tais como: questões domésticas (por exemplo, ausência do companheiro na educação dos filhos), falta de tempo, sua própria história escolar, a culpa que sentem pelas dificuldades dos filhos e o receio de participar de reuniões, pois apenas as falhas seriam apontadas. Além disso, quando decidem realmente participar e questionar, a escola simplesmente sugere a transferência do aluno como a única forma de resolver os problemas, rompendo, dessa forma, com a relação (Giorgion, 2011).

Tanto a saúde quanto a educação pública foram profundamente afetadas pelas políticas de ajuste econômico dos anos 1990, e o resultado foi o sucateamento da escola pública, a baixa qualidade do ensino, a insuficiência de recursos de forma geral e a desvalorização profissional, entre outras. Como consequência, os professores se depararam com baixos salários, além de ambientes desconfortáveis, incômodos e intranquilos, exigindo deles um esforço ainda maior, tanto física quanto mentalmente, trazendo repercussões negativas sobre a sua saúde, comprometendo a qualidade de vida desse grupo populacional (Souza et al., 2003; Gasparini, Barreto e Assunção, 2006; Araújo et al., 2003).

Somada a isso, há a necessidade dos professores de acompanhar a evolução das tecnologias, uma vez que, hoje, os alunos possuem fácil acesso às informações e avaliam e desafiam constantemente os docentes em sala de aula. Utilizar essas tecnologias e meios de comunicação de massa facilita a transmissão do conteúdo por causa da grande força de penetração do docente (Nóvoa, 1999). De acordo com Mariano e Muniz (2006), existe todo um esforço para preparar as aulas com antecedência, mesmo com falta de tempo, pois dominar o conteúdo significa ter menos angústia e maior controle da situação.

As condições salariais também foram consideradas ruins ou regulares para $62,8 \%$ dos entrevistados. Os baixos salários trazem insatisfações, dissabores e sobrecarga de trabalho, pois, como foi discutido anteriormente, o professor precisa trabalhar em vários turnos, assim como desenvolver outra atividade remunerada na tentativa de aumentar seus rendimentos salariais, uma vez que eles não atendem às reais necessidades dos docentes e de suas famílias (Mariano e Muniz, 2006). Diante disso, vários membros da família precisam trabalhar para complementar a renda e garantir determinado padrão de vida (Codo, 1999). 
Para Codo (1999), a escola é uma das piores organizações para trabalhar por conta dos salários baixos, das condições precárias de trabalho e por causa da pouca perspectiva de progressão na carreira. No entanto, apesar dos fatores negativos apontados no dia a dia do trabalho de professor, neste estudo, 44,7\% dos entrevistados disseram sentir-se realizados, e 81,1\% motivados para chegar ao trabalho. Afirmaram, também, ter oportunidade de expressar suas opiniões. Em pesquisa realizada com professores espanhóis, $34 \%$ dos docentes se sentiam felizes, eficientes e realizados trabalhando no magistério, respondendo de forma efetiva às exigências e transformações a que a profissão docente se viu submetida (Esteve, 1999).

Ter oportunidade para expressar opiniões no trabalho é fundamental, e esses espaços de discussão são cruciais para a preservação da saúde mental, pois os trabalhadores sentem-se mais felizes em poder participar, o que estimula, consequentemente, a cooperação do grupo, além de reduzir o absenteísmo e também os riscos de acidentes de trabalho (Lancman e Sznelwar, 2004).

$\mathrm{O}$ não reconhecimento social do trabalho docente acaba por se refletir em condições de trabalho precárias e na baixa remuneração, que constituem uma fonte cíclica de transtornos e estresse para os professores. Fica a cargo do professor compensar e superar as precárias condições de trabalho. Tal situação pode ser verificada quando se analisam as cargas de trabalho, em especial, as cargas físicas e psíquicas. Em situações ambientais e técnicas precárias, cabe ao professor compensar os desequilíbrios estruturais à custa de seus próprios recursos cognitivos e biológicos. Neste estudo, a maioria dos professores relata que essas cargas de trabalho afetam muito o seu trabalho. A carga psíquica, que afeta muito as condições de trabalho e de saúde dos professores pesquisados, por ser dinâmica e qualitativa, não é mensurável, pois é inscrita na subjetividade, porém é real quando relacionada às pressões e exigências cotidianas do trabalho (Dejours, Abdoucheli e Jayet, 1994).

Os docentes, diariamente, são expostos a essas pressões e exigências, e quanto maiores são as demandas da escola, mais complexas se tornam suas atividades. A organização do sistema escolar e do ensino, hoje centrada no saber e nos conteúdos, impõe aos professores o desenvolvimento de novas competências, às quais, em muitos casos, eles não se sentem preparados para atender. A gestão escolar exige do professor, porém não fornece os recursos necessários para o pleno desenvolvimento do seu trabalho (Assunção, 2008; Assunção e Oliveira, 2009).

Dessa forma, o trabalho do docente não se restringe apenas à sala de aula, e esse excesso de atividades, que exige responsabilidades e compromissos, dificilmente é cumprido dentro do ambiente escolar, embora, por direito, o professor tenha a chamada hora-atividade (destinada ao preparo dos conteúdos ministrados em sala de aula e prevista na Lei de Diretrizes e Bases da Educação, de 1996). Com isso, ele se vê obrigado a levar para seu 
domicílio as tarefas que não conseguiu concluir durante o horário de trabalho, aumentando, com isso, a sua carga horária, que já é intensa. Para Souza (2009), o trabalho invade a vida pessoal do professor, impedindo que ele desfrute de momentos de reflexão, criatividade e ociosidade.

O ritmo intenso de trabalho (resultante do curto espaço entre uma aula e outra), os vários deslocamentos entre os colégios, os contatos com supervisores em momentos de descanso (como no horário do intervalo) e o excesso de atividades (Silvany Neto et al., 2000) têm como consequência, segundo Esteve (1999), o chamado "mal-estar docente", decorrente dos efeitos negativos permanentes que afetam a personalidade do professor, resultantes, por sua vez, das condições psicológicas, dos ambientes sociais e de trabalho em que se exerce a docência. O mesmo autor diz ainda que "o 'mal-estar docente' é uma doença social produzida pela falta de apoio da sociedade aos professores, tanto no terreno dos objetivos do ensino como no das recompensas materiais e no reconhecimento do status que lhe atribui" (1999, p. 144).

Trabalhar sob essa pressão também desfavorece o desenvolvimento de estratégias que visem proteger a saúde, como escolher posturas mais adequadas e confortáveis e evitar o abuso vocal (Assunção e Oliveira, 2009). Além disso, e como consequência, podem surgir os problemas de saúde e a necessidade de se ausentar do trabalho.

De acordo com a Agência Europeia para a Saúde e Segurança no Trabalho, milhões de trabalhadores europeus são expostos todos os dias em seus locais de trabalho ao barulho e a todos os riscos que ele pode acarretar; o excesso de ruído, apesar de mais evidente em indústrias e setores da construção civil, pode ser encontrado em outros ambientes, como bares e restaurantes, assim como em escolas (European Agency for Safety and Health at Work, 2005). E no Brasil não é diferente, como no caso deste estudo e de vários outros mencionados anteriormente.

A exposição ao ruído pode causar uma série de problemas relacionados à saúde e à segurança dos trabalhadores, tais como: perda auditiva, efeitos fisiológicos no sistema cardiovascular, por exemplo, que resulta na liberação de catecolaminas e aumento da pressão sanguínea, estresse no trabalho e aumento do risco de acidentes de trabalho (European Agency for Safety and Health at Work, 2005).

No caso dos professores, além de alguns desses riscos, o ruído elevado, dentro ou fora da sala de aula, esteve associado aos transtornos mentais (Gasparini, Barreto e Assunção, 2006) e à pior qualidade de vida relacionada à voz, no domínio físico (segundo o protocolo de qualidade de vida e voz) (Jardim, Barreto e Assunção, 2007). Esses ruídos, muitas vezes potencializados em escolas onde há intervalos em diferentes horários, combinados a fatores psíquicos, podem levar a um ambiente de trabalho estressante (Silvany Neto et al., 2000). 
Quanto à exposição ao pó de giz, referida como "afeta muito" pelos professores desta pesquisa, Palheta Neto et al. (2008), ao compararem o uso do giz para escrever no quadro com o pincel atômico e ao relacioná-los a problemas com a voz, no caso, rouquidão, não encontraram diferença significativa. Esses autores, porém, citam diversos estudos que comprovam que professores que utilizam o giz estão mais propensos a ter problemas relacionados à voz, pois o fato de falar voltado para o quadro, inalando o pó do giz, irrita a laringe, provocando secura e rouquidão, além de outros problemas respiratórios e alérgicos. Os mesmos autores citam, também, estudos que apontam os benefícios do uso do pincel atômico no lugar do giz.

Nesta pesquisa, devido ao desenho metodológico adotado, há restrições quanto a uma análise mais abrangente sobre a percepção do trabalhador com relação ao processo de trabalho. Destacam-se, também, as frequências negativas observadas no estudo, que podem ter sido subestimadas nesta pesquisa, uma vez que os trabalhadores com piores condições de saúde ou que percebem de maneira mais negativa as suas condições de trabalho tendem a ter maior quantidade de afastamentos ou mesmo abandono precoce de carreira. Durante a coleta de dados, os pesquisadores se viram diante de situações vivenciadas pelos professores, tais como: conflitos, tensões, insegurança, sobrecarga (cuidar de duas turmas ao mesmo tempo, devido à falta de corpo docente), momentos de revolta, emoção e sofrimento, que devem ser aprofundadas em outros tipos de estudo.

\section{Conclusão}

As políticas de ajustes econômicos implantadas nas últimas décadas trouxeram grandes consequências para a escola pública no tocante às condições de trabalho, organização e gestão. Os professores, afetados diretamente por essas mudanças, depararam-se com condições precárias de trabalho, desde a falta de recursos materiais e financeiros até sua desvalorização perante a sociedade. Somado a isso, o professor, hoje, se vê obrigado a acompanhar as evoluções tecnológicas, uma vez que seus alunos possuem fácil acesso às informações e os avaliam e desafiam constantemente em sala de aula. Como consequência, há uma intensificação de seu trabalho, gerando sobrecarga.

A maior parte dos professores entrevistados era de mulheres, brancas e com média de idade de 41,5 anos. A maioria vivia com companheiro e possuía, ao menos, especialização.

Os professores deste estudo referiram como negativos os fatores referentes às condições de trabalho (infraestrutura, remuneração, quantidade de alunos por sala, entre outros). Foram considerados positivos os relacionamentos no ambiente de trabalho com os diversos atores que compõem o 
cenário escolar (alunos, colegas, diretores), assim como a motivação e a oportunidade para expressar suas opiniões (para mais de $80 \%$ deles).

As condições de trabalho precárias refletiram-se também na percepção das cargas físicas, fisiológicas e psíquicas. Destaque para os altos percentuais de avaliação negativa das cargas fisiológicas e psíquicas, que demonstram o resultado da compensação empreendida pelos professores na busca de superar as precárias condições de trabalho. Os professores relataram, também, uma elevada carga horária semanal. Uma significativa parcela dos entrevistados trabalha em três ou mais escolas e em três turnos. Verificouse que $31,3 \%$ dos entrevistados tinham contratos temporários. Essa forma de inserção no mercado de trabalho gera instabilidade e ausência de benefícios, como de saúde, e progressões na carreira, que são garantidos aos professores estatutários.

Como contribuição deste estudo, destaca-se o mapeamento das condições de trabalho dos professores da rede pública, que poderá servir de subsídio para o desenvolvimento de políticas públicas que visem a melhorias no trabalho e na vida dos professores de forma geral. Valorizar o trabalho do professor é compreender a importância da educação e desse profissional para a construção de uma sociedade mais justa e comprometida.

\section{Colaboradores}

Todos os autores tiveram contribuição substancial no projeto e delineamento, no levantamento de dados ou na sua análise e interpretação. 
Resumen El objetivo fue describir el perfil sociodemográfico y económico y analizar las características profesionales, condiciones de trabajo y cargas de trabajo en maestros. Se trata de un estudio transversal sobre el proyecto Pró-Mestre. Fueron entrevistados 978 maestros de la educación primaria y secundaria de las vente escuelas con mayor número de maestros de la red estadual de enseño de la ciudad de Londrina/PR, Brasil, entre agosto de 2012 y julio de 2013. La mayoría de los maestros entrevistados era del sexo femenino $(68,5 \%)$ y con media de edad de 41,5 años (DP 10). Cuanto a las características profesionales, $42,9 \%$ trabajaban en até dos locales y $64,2 \%$ lesionaban en por lo menos dos turnos. Aspectos como remuneración, cuantidad de estudiantes por sala e infraestructura fueron relatados como negativos (mal/regular). En relación a las cargas de trabajo, las cargas físicas, fisiológicas y psíquicas, para más de la mitad de ellos, afectan mucho su salud y condiciones de trabajo. Esos factores señalizaron las condiciones de trabajo y salud de maestros de la red estadual del Paraná, sirviendo como subsidio para el desarrollo de políticas públicas que visen mejorías en eses aspectos.

Palabras clave trabajo docente; maestro; condiciones de trabajo; cargas de trabajo.

\section{Notas}

1 Universidade Estadual de Londrina, Paraná, Brasil.

$<$ natalia-uel@hotmail.com>

Correspondência: Rua Dr. Clóvis De Arruda Campos, 26, Vila Bandeirantes, CEP 16015-570, Araçatuba, São Paulo, Brasil.

2 Universidade Estadual de Londrina, Centro de Ciências da Saúde, Departamento de Saúde Coletiva, Londrina, Paraná, Brasil.

<alnunes.3@gmail.com>

3 Universidade Estadual de Londrina, Centro de Ciências da Saúde, Departamento de Saúde Coletiva, Londrina, Paraná, Brasil.

<betoduran80@gmail.com>

4 Universidade Estadual de Londrina, Centro de Ciências da Saúde, Departamento de Saúde Coletiva, Londrina, Paraná, Brasil.

$<$ aemesas@hotmail.com>

5 Baseado em dissertação e subvencionado pela CAPES (bolsa de Mestrado). Não há conflito de interesses. 


\section{Referências}

ARAUJO, Tânia M. et al. Saúde e trabalho docente: dando visibilidade aos processos de desgaste e adoecimento docente a partir da construção de uma rede de produção coletiva. Educação em Revista, Belo Horizonte, n. 37, p. 183-212, jul. 2003. Disponível em: <http://educa.fcc.org.br/pdf/edur/n37/ n37a13.pdf>. Acesso em: 23 maio 2012.

ASSUNÇÃO, Ada A. Saúde e mal-estar do(a) trabalhador(a) docente. IN: VII SEMINÁRIO REDESTRADO NUEVAS REGULACIONES EN AMÉRICA LATINA, 2008, Buenos Aires. Anais... Buenos Aires, 2008. Disponível em: <www.fae.ufmg.br/estrado/cdrom_seminario_ 2008/textos/ponencias/Ponencia\%20Ada $\% 20$ Avila.pdf>. Acesso em: 23 jul. 2012.

ASSUNÇÃO, Ada A.; OLIVEIRA, Dalila A. intensificação do trabalho e saúde dos professores. Educação \& Sociedade, Campinas, v. 30, n. 107, p. 349-372, Aug. 2009. Disponível em: <www.scielo.br/scielo.php?pid= S0101-73302009000200003\&script $=$ sci_ arttext> Acesso em: 24 abr. 2012.

BRASIL. Ministério da Educação. Lei n. 9.394, de 1996. Lei de Diretrizes e Bases da Educação. Estabelece as diretrizes e bases da educação nacional e legislação correlata. 2 . ed. Brasília: Câmara dos Deputados, Coordenação de Publicações. 2001.

Brasil. Ministério do Trabalho e Previdência Social. 2013. Disponível em: <http://portal. mte.gov.br/sal_min/> Acesso em: 10 set. 2013.

CODO, W. Educação: carinho e trabalho. Petrópolis: Vozes, 1999. 432 p.

CRUZ, Roberto M. et al. Saúde docente, condições e carga de trabalho. Revista Electrônica de Investigación y Docencia (REID), Jaén, v. 4, p. 147-160, jul. 2010. Disponível em: $<$ www.revistareid.net/revista/n4/REID4art8. pdf> Acesso em: 24 abr. 2012.

DEJOURS, Christophe. A loucura do trabalho: estudo de psicopatologia do trabalho. 5 ed ampl. São Paulo: Cortez - Oboré, 1992. $168 \mathrm{p}$.

DEJOURS, Christophe; ABDOUCHELI, Elisabeth; JAYET, Christian. Psicodinâmica do trabalho: contribuições da escola dejouriana à análise da relação prazer, sofrimento e trabalho. São Paulo: Atlas, 1994. 144p.

ESTEVE, José M. O mal-estar docente: a sala de aula e a saúde dos professores. 3. ed. Bauru: EDUSC, 1999. 176p.

European Agency for Safety and Health at Work. An introduction to noise at work. Facts. 2005. Disponível em: <https://osha.europa. $\mathrm{eu} / \mathrm{en} /$ publications/factsheets/56>. Acesso em: 15 set. 2013

FACCHINI, Lys A. “Uma contribuição da epidemiologia: o modelo da determinação social aplicado à saúde do trabalhador". In: BUSCHINELLI, José T. P.; ROCHA, Lys. E. ; RIGOTTO, Raquel M. (Org.). Isto é trabalho de gente?: vida, doença e trabalho no Brasil. São Paulo: Vozes, 1993. p. 178-186.

FRANCO, Tania; DRUCK, Graça; SELIGMANN-SILVA, Edith. As novas relações de trabalho, o desgaste mental do trabalhador e os transtornos mentais no trabalho precarizado. Revista Brasileira de Saúde Ocupacional, São Paulo, v. 35, n. 122, p. 229-248, jul./dez. 2010. Disponível em: <www.scielo.br/scielo. php?pid=S0303-76572010000200006\&script $=$ sci_arttext> Acesso em: 10 set. 2013.

GASPARINI, Sandra M.; BARRETO, Sandhi M.; ASSUNÇÃO, Ada A. O professor, as condições de trabalho e os efeitos sobre sua saúde. Educação e Pesquisa, São Paulo, v. 31, n. 2, p. 189-199, maio/ago. 2005. Disponível em: $<$ www.scielo.br/pdf/ep/v31n2/a03v3ln2. pdf>. Acesso em: 24 abr. 2012.

GASPARINI, Sandra M.; BARRETO, Sandhi M.; ASSUNÇÃO, Ada A. Prevalência de transtornos mentais comuns em professores da rede municipal de Belo Horizonte, Minas 
Gerais, Brasil. Cadernos de Saúde Pública, Rio de Janeiro, v. 22, n. 12, p. 2679-2691, dez. 2006. Disponível em: <www.scielo.br/pdf/ csp/v22n12/16.pdf > . Acesso em: 24 abr. 2012.

GIORGION, Mariana C. P. O contexto de não texto. Campos relacionais de pais e escola. 2011. 137f. Dissertação (Mestrado em Educação) - Universidade de São Paulo, São Paulo, 2011.

JARDIM, Renata; BARRETO, Sandhi M.; ASSUNÇÃO, Ada A. Condições de trabalho, qualidade de vida e disfonia entre docentes. Cadernos de Saúde Pública, Rio de Janeiro, v. 23, n. 10, p. 2439-2461, out. 2007. Disponível em: <www.scielo.br/scielo.php?pid= S0102-311X2007001000019\&script $=$ sci_ arttext>. Acesso em: 15 ago. 2012.

LANCMAN, Selma; SNELWAR, Laerte I. Cristophe Dejours: da psicopatologia à psicodinâmica do trabalho. Rio de Janeiro: Editora Fiocruz, Brasília: Paralelo, 2004. 346 p

MARIANO, Maria S. S.; MUNIZ, Helder P. Trabalho docente e saúde: o caso dos professores da segunda fase do ensino fundamental. Estudos e Pesquisas em Psicologia, Rio de Janeiro, ano 6, n. 1, p. 76-88, jan./jun. 2006. Disponível em: <www.revispsi.uerj. br/v6nl/artigos/PDF/v6nla07.pdf $>$ Acesso em: 15 out. 2012.

MATIAS, Marias C. M.; ABIB, José. A. D. Sociedade em transformação: estudo das relações entre trabalho, saúde e subjetividade. Londrina: EDUEL, 2007. 316 p.

NÓVOA, Antonio. Profissão professor. 2 ed. Porto: Porto Editora, 1999. 191p.

PALHETA NETO, Francisco X. et al. Relação entre as condições de trabalho e a autoavaliação em professores do ensino fundamental. Arquivos Internacionais de Otorrinolaringologia, São Paulo, v. 12, n. 2, p. 230-238, abr./jun. 2008. Disponível em: <www.international archivesent.org/additional/acervo_port. asp? Id=519> . Acesso em 16 fev. 2013.
PENA, Paulo G. L.; MINAYO-GOMEZ, Carlos. Premissas para a compreensão da saúde dos trabalhadores no setor serviço. Saúde e Sociedade, São Paulo, v. 19, n. 2, p. 371-383, jun. 2010. Disponível em: <www6.ensp. fiocruz.br/repositorio/sites/default/files/ arquivos/Premissas.pdf $>$ Acesso em: 18 set. 2013.

PENA, Paulo G. L. Aspectos conceituais do setor de serviços e a saúde do trabalhador. In: MINAYO-GOMEZ, Carlos; MACHADO, Jorge M. H.; PENA, Paulo G. L. Saúde do trabalhador na sociedade brasileira contemporânea. Rio de Janeiro: FIOCRUZ, 2011. p. 411-432.

RIO GRANDE DO SUL. Associação Comercial, Industrial e de Serviços de Novo Hamburgo, Campo Bom e Estância Velha. 2013. Disponível em: <www.acinh.com.br/cotacao. html $>$ Acesso em: 10 set. 2013.

SANTOS, Catarina A. et al. Avaliação de desempenho docente nas redes estaduais de educação básica no Brasil. Anais... III Congresso Ibero Americano de Politica e Administração da Educação, 2012. Disponível em: <www.anpae.org.br/iberoamericano2012/ Trabalhos/CatarinadeAlmeidaSantos_res_ int_GT2.pdf> Acesso em: 20 maio 2015.

SILVANY NETO, Annibal M. et al. Condições de trabalho e saúde de professores da rede particular de ensino de Salvador, Bahia. Revista Baiana de Saúde Pública, Salvador, v. 24 , n. 1/2, p. 42-56, jan./dez. 2000. Disponível em: <http://inseer.ibict.br/rbsp/ index.php/rbsp/article/viewFile/103/100>. Acesso em: 23 jul. 2012.

SOUZA, Katia R. de et al. A trajetória do sindicato estadual dos profissionais da educação do Rio de Janeiro (SEPE-RJ) na luta pela saúde no trabalho. Ciência \& Saúde Coletiva, São Paulo, v. 8, n. 4, p. 1057-1068, 2003. Disponível em: <www.scielo.br/pdf/ csc/v8n4/a27v8n4.pdf $>$ Acesso em: 16 out. 2012 . 
SOUZA, Luiz A. A. de. Trabalho docente: reflexões acerca da condição de trabalho e valorização do professor da escola pública. In: IX CONGRESSO NACIONAL DE EDUCAÇÃO - EDUCERE - III ENCONTRO SUL BRASILEIRO DE PSICOPEDAGOGIA, 2009, Curitiba. Anais... Curitiba: PUCPR, 2009. Disponível em: <www.pucpr.br/eventos/ educere/educere2009/anais/pdf/2692_1603. pdf $>$ Acesso em: 16 out. 2012.

Recebido em 22/07/2014

Aprovado em 25/05/2015 